\title{
The modelling of power plant's evaporative cooling tower operation taking into account hydrometeorological conditions
}

\author{
Alexander Solovyev ${ }^{1}$, Dmitriy Solovyev ${ }^{2,3}$, Liubov Shilova, ${ }^{4, *}$, and Aleksey Adamtsevich ${ }^{4}$ \\ ${ }^{1}$ Lomonosov Moscow State University, Department of Geography, 119991, Leninskie gory, 1/19, \\ GSP-1 Moscow, Russian Federation \\ ${ }^{2}$ Shirshov Institute of Oceanology, Russian Academy of Sciences, 117997, Nakhimovsky Prospect, \\ 36, Moscow, Russian Federation \\ ${ }^{3}$ Joint Institute for High Temperatures, Russian Academy of Sciences, 125412, Izhorskaya, 13/ 2 , \\ Moscow, Russian Federation \\ ${ }^{4}$ Moscow State University of Civil Engineering (National Research University), 129337, \\ Yaroslavskoye chosse, 26, Moscow, Russian Federation
}

\begin{abstract}
The paper aims to perform numerical modelling of the operation of large-scale evaporative cooling towers of power plants considering dynamically changing hydrometeorological conditions. The proposed modelling was performed based on the developed mathematical algorithm for studying the influence of turbulent vortex motions on the processes of atmospheric cooling of circulating water in countercurrent cooling towers of power plants. According to the simulation results, the optimal heat exchange modes of cooling towers operation are determined and recommendations for the practical implementation of measures to improve their thermal efficiency in hot periods of the year are proposed.
\end{abstract}

\section{Introduction}

The heat removal from power plants turbines is dictated by the laws of thermodynamics. The efficiency of the Rankine cycle used in power plants depends on the initial and final parameters (pressure and temperature) of steam. In large installed power plants, only one-third of the heat generated by the reactor is used to generate electricity. The remaining two-thirds are transferred to the external absorber. This function can be performed by a cooling pond or cold atmospheric air passing through evaporative "wet" cooling towers (towers with circulating water from power plant turbines) [1].

The process of cooling water in wet evaporative cooling towers occurs due to partial evaporation of water (evaporation) and heat exchange with a counter-flow of air. Part of the evaporated water in the form of droplets is captured by a stream of flow and air and falls near

\footnotetext{
* Corresponding author: ShilovaLA@mgsu.ru
} 
the cooling tower in the form of precipitation (drip entrainment). The loss of water is replenished by recharge water from reservoirs [2].

During operation of power plants, the most acute problem is the use of cooling equipment for circulating water, especially in the summer hot period of the year, when the air temperature slightly differs from the temperature of the water supplied from the turbines for cooling [3]. The climatic changes occurring in recent years with long periods high temperatures and shallowing of cooling ponds in reservoirs have a negative impact on the sustainability of standard operating conditions cooling systems of power plants. The study of the influence of meteorological conditions on the reduction of the operating efficiency of evaporative cooling towers (ECT) will make it possible to develop recommendations for the practical implementation of energy and resource-saving technologies, ensure safe operation and improve the ecological situation in areas adjacent to nuclear power plants (NPP) evaporative cooling towers $[4,5]$.

In most research works, the problem of cooling towers is regarded only as technical [6-9]. Basic research is practically absent. There is an obvious lag in the formulation of tasks corresponding to the current state of scientific knowledge in the study of essentially non-equilibrium and non-linear phenomena inherent in the processes of mass, heat and momentum transfer in coupled aerothermodynamic systems of inhomogeneous media.

The solving of the problem of ensuring the effective operation of cooling and restoring hot water temperature coming out of the condensers of power plant turbines is considered in the literature about cooling towers as purely technical task without peculiarities of non-equilibrium and non-linear phenomena inherent in mass, heat and momentum transfer processes in coupled hydrodynamic systems of inhomogeneous media [6-9]. The paper aims are to perform a numerical simulation of the evaporative cooling tower operation based on the developed mathematical algorithm [10], highlighting the influence of turbulent vortex motions on the air cooling of circulating water in evaporative tower large-scale cooling towers of power plants, considering changing hydrometeorological conditions. The main aim of this research work is to determine the optimal operation modes of the cooling tower according to results of simulation and offer recommendations for the practical implementation of measures to improve the efficiency of their work.

\section{Theoretical numerical study of the hydrodynamic parameters of the vapour-air flow}

\subsection{System of equations for the numerical model of the evaporative cooling tower}

Evaporative cooling towers are widely used to remove heat in the circulating water supply systems of modern power plants. The heated water entering the cooling tower, intended for cooling, is supplied through the piping system, is evenly distributed and sprayed by spray nozzles on the sprinkler. Under the action of gravity, water flows down the irrigation nozzle into the drainage basin. Air enters the cooling tower through air inlet windows located at the bottom of the cooling tower. Heat and mass transfer occurs between the water cooled in the cooling tower and atmospheric air. The theoretical limit of water cooling for evaporative cooling is the temperature of the wet thermometer [11].

The design parameters of cooling towers are determined by technical and economic calculations depending on the volume and temperature of the cooled water and the parameters of the atmosphere (temperature, humidity, etc.) at the installation site [12, 13]. For thermal calculation of cooling towers and analysis of heat and mass transfer processes in it, the 
developed mathematical model is applied $[10,14]$, in which the evaporative cooling of water droplets moving in an air stream is described by a system of the following ordinary differential equations:

$$
\begin{gathered}
\frac{\partial \bar{U}}{\partial t}+(\bar{U} \nabla) \bar{U}=-\frac{1}{\rho} \nabla p+v \Delta \bar{U}+\bar{g}-2[\bar{\Omega} \times \bar{U}] \\
\frac{\partial \rho}{\partial t}+\operatorname{div}(\rho \vec{U})=0 \\
\frac{\partial T}{\partial t}+(\vec{U} \nabla) T=\lambda \Delta T \\
\rho=\rho(T) \\
\frac{d G_{w}\left(x_{3}\right)}{d x_{3}}=-\gamma B \cdot\left[\rho_{s}\left(x_{3}\right)-\rho_{v}\left(x_{3}\right)\right] \\
\frac{d G_{v}\left(x_{3}\right)}{d x_{3}}=\gamma B \cdot\left[\rho_{s}\left(x_{3}\right)-\rho_{v}\left(x_{3}\right)\right] \\
\frac{d}{d x_{3}} J_{a}\left(x_{3}\right)=\alpha b \cdot\left[T_{w}\left(x_{3}\right)-T_{a}\left(x_{3}\right)\right] \\
\frac{d}{d x_{3}} J_{v}\left(x_{3}\right)=-b \cdot\left\{\alpha \cdot\left[T_{w}\left(x_{3}\right)-T_{a}\left(x_{3}\right)\right]-r \cdot \gamma \cdot\left[\rho_{s}\left(x_{3}\right)-\rho_{v}\left(x_{3}\right)\right]\right\}
\end{gathered}
$$

Here $\bar{U}$ is the velocity vector; $T$ is a temperature; $p$ is a pressure; $\rho$ is the density; $g$ is the acceleration of gravity; $t$ is a time; $v$ and $\lambda$ are the coefficients of molecular viscosity and thermal conductivity; $\Omega$ is the angular velocity of rotation; $J$ is a specific enthalpy (heat content), $\mathrm{J} / \mathrm{kg}(\mathrm{kcal} / \mathrm{kg}) ; G$ is a mass flow $(\mathrm{kg} / \mathrm{s}) ; F$ is the irrigation area, $\mathrm{m}^{2} ; b$ is a sprinkler height, $\mathrm{m} ; B$ is the sprinkler width, $\mathrm{m} ; \varphi$ - relative humidity, $\% ; r=2493 \mathrm{~kJ} / \mathrm{kg}(595 \mathrm{kcal} / \mathrm{kg})$ is the specific heat of vaporization; $\alpha$ is a heat transfer coefficient, $\mathrm{W} /\left(\mathrm{m}^{2 \circ} \mathrm{C}\right) ; \gamma$ is the mass transfer coefficient, $\mathrm{kg} /\left(\mathrm{m}^{3} \mathrm{~s}\right)$.

The designations of the indices in the equation system (1) are performed as follows: $a$ - (air) air; $s$-saturated; $v$ - (vapor) steam; $w$ - water; 1 - at the entrance to the cooling tower, $2-$ at the exit of the cooling tower.

All equations belong to the right Cartesian coordinate system with axes $\left(x_{1}, x_{2}, x_{3}\right)$, coinciding with the direction of motion of the right-rotating screw. For the origin is taken the upper left corner. Axis $x_{1}$ is directed at us, axis $x_{3}$ is directed vertically up, and axis $x_{2}$ is directed to the right.

We write the converted thermohydroaerodynamics system of equations (1) in an index form according to the Boussinesque's approximation:

$$
\begin{gathered}
\frac{\partial U_{i}}{\partial t}+U_{j} \frac{\partial U_{i}}{\partial x_{j}}=-\frac{1}{\rho_{0}} \frac{\partial P}{\partial x_{i}}+v \frac{\partial^{2} U_{i}}{\partial x_{j} \partial x_{j}}-g\left(1-\frac{\tilde{T}}{T}\right) \delta_{i 3}-2 \Omega\left[\left(U_{1} \delta_{i 2}-U_{2} \delta_{i 1}\right)\right. \\
\frac{\partial T}{\partial t}+U_{j} \frac{\partial T}{\partial x_{j}}=\lambda \frac{\partial^{2} T}{\partial x_{j} \partial x_{j}} \\
\frac{\partial U_{i}}{\partial x_{i}}=0 \\
\rho(T)=\rho_{0}(\tilde{T})-\rho_{0}(\tilde{T})\left(1-\frac{\tilde{T}}{T}\right) \\
\frac{d G_{w}\left(x_{3}\right)}{d x_{3}}=-\gamma B \cdot\left[\rho_{s}\left(x_{3}\right)-\rho_{v}\left(x_{3}\right)\right]
\end{gathered}
$$




$$
\begin{gathered}
\frac{d G_{v}\left(x_{3}\right)}{d x_{3}}=\gamma B \cdot\left[\rho_{s}\left(x_{3}\right)-\rho_{v}\left(x_{3}\right)\right] \\
\frac{d}{d x_{3}} J_{a}\left(x_{3}\right)=\alpha b \cdot\left[T_{w}\left(x_{3}\right)-T_{a}\left(x_{3}\right)\right] \\
\frac{d}{d x_{3}} J_{v}\left(x_{3}\right)=-b \cdot\left\{\alpha \cdot\left[T_{w}\left(x_{3}\right)-T_{a}\left(x_{3}\right)\right]-r \cdot \gamma \cdot\left[\rho_{s}\left(x_{3}\right)-\rho_{v}\left(x_{3}\right)\right]\right\}
\end{gathered}
$$

where $\rho_{0}$ is a density of air at $T_{0}=200^{\circ} \mathrm{C}\left(1.205 \mathrm{~kg} / \mathrm{m}^{3}\right), \delta_{i j}$ is the Kronecker symbol,

$$
\alpha=\frac{0,025 \cdot \lambda_{a} \cdot \mathrm{Re}^{4 / 5}}{b-x_{3}}, \gamma=\frac{0,025 \cdot D_{a} \cdot \mathrm{Re}^{4 / 5}}{b-x_{3}} .
$$

The Reynolds number [15] for airflow past a flat sprinkler plate is calculated as follows $\operatorname{Re}=\frac{\left(b-x_{3}\right) \cdot U_{a}}{v_{a}}$. Air enthalpy $J_{a}=C_{a} T_{a}$, vapour enthalpy $J_{v}=\left(r+C_{v} T\right) L$, moisture content $L=\frac{\varphi \rho_{s} R_{v} T}{P_{a}-\varphi P_{s}}$.

The density and pressure of saturated steam $\rho_{s}, P_{s}$ at the corresponding temperature $T$ is calculated using the reference tables or formula $\rho=0,005417 \varphi e^{0,0558 T}\left(\mathrm{~kg} / \mathrm{m}^{3}\right)$, and irrigation density $q$ is the ratio of the amount of cooled water $G$ to the cooling tower area $F[16]$.

\subsection{Setting the boundary conditions for the evaporative cooling tower numerical model}

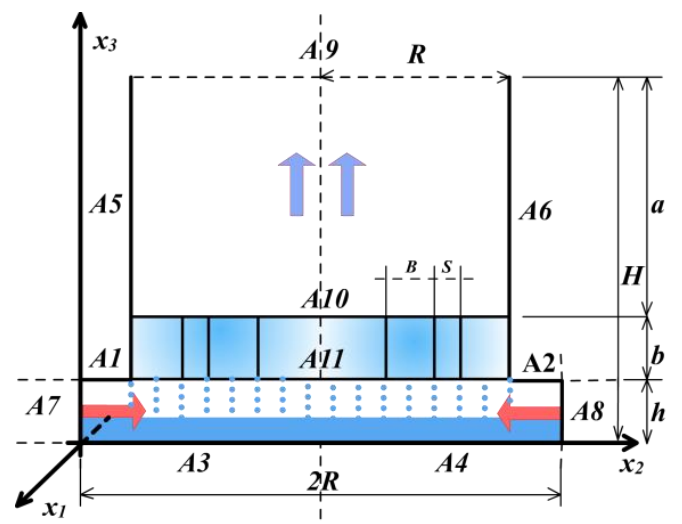

Fig. 1. The scheme of the computational region of the evaporative cooling tower.

The boundary conditions for the system of equations (2) are written as follows:

At $0 \leq x_{3} \leq h$ (in the lower section of the tower at the entrance to its growing space $A 1=A 2$, $A 7=A 8$ ) these parameters are set: the outside air temperature $T_{l a}$, its humidity $\varphi$ and pressure $P_{\text {and }}$, heat flow $-C_{a} \rho_{a} \lambda_{a} \frac{\partial T_{a}}{\partial x_{3}}=Q\left(x_{2}\right)$, air enthalpy $J_{a l}$, the rate of incoming flows of the tower, twist flow and air flow $U_{1}=U_{1}^{i n}, U_{2}=U_{2}^{i n}, \Omega=\frac{U^{i n}}{R} \sin \chi, G_{a}$, where $\chi$ is an upstream space irrigation angle measured from the radial direction, $R$ - the radius of the support ring 
of the tower; at $x_{3}=b+h$ (in the upper section of the sprinkler $A 3, A 4$ ) the initial water flow rate $G_{w}$, water temperature $T_{l w}$, vapour enthalpy $J_{a l}$ for the initial water temperature are set.

Geometric characteristics of the cooling tower are the tower radius $R$, distance between the sprinkler sheets $S$, height of the sprinklers $b$, and width of each sprinkler $B$; height of input windows in the growing space $h$, irrigation area $F$, irrigation density $q$, height of the tower and distance from the irrigator to the upper end of the tower.

The implementation of the adequate mathematical model of the cooling tower required efficient computing tools and was implemented in the mathematical package Matlab R2017. The following parameters of the numerical scheme were used in the calculations: the number of points along the height of the cooling tower is 4300 ; the number of points across the base of the cooling tower is 6300 ; dimensionless step height $H$ is 0.02 ; dimensionless step width $2 R-0.01$; dimensionless time step -0.05 .

\subsection{Calculation of the thermal efficiency of the cooling tower}

I- $d$ diagram of humid air at atmospheric pressure can be used for determining the temperature of a wet thermometer $\tau$ [17]. The calculation of thermal efficiency cooling towers must be expressed in terms of water temperature differential to the ratio (index - in) and after (index - out) cooling to the difference of the initial temperature and ultimate temperature of wet thermometer $\eta=\frac{T_{\text {in }}-T_{\text {out }}}{T_{\text {in }}-\tau}$ [1]. The changing of the saturation adjustment ratio characterizes the state of the nozzle components in aqueous vapour mixture and by the ratio $\Delta K_{H}=\left(G_{v}+G_{s}\right) / G_{v \max }$. Wherein, $\Delta K_{H}<1$ correspond to unsaturated moist air, $\Delta K_{H}>1-$ saturated moist air with dispersed condensed phase (fog).

\section{The results of the numerical calculation of the parameters of hydro-air-thermodynamic processes in evaporative cooling towers taking into account the hydrometeorological conditions}

\subsection{Setting the initial parameters for numerical calculations}

The parameters of the industrial cooling tower of NPP and its reduced laboratory model [10] were used as initial parameters for the simulation of the cooling tower. Typical averaged characteristics of the most Russian NPP's evaporative cooling tower used at were used as dimensional parameters of a full-scale cooling tower.

The numerical experiment included four series of calculations with variation of the following parameters: water and air temperature at the inlet to the cooling tower $T_{w}$ in and $T_{a}$ in ; relative air humidity $\varphi$; ratios of air and water flow rates $Q_{a}$ and $Q_{w} ; \Omega$ is the angular velocity of the air rotation, which is determined by the angle of entry of the flow into the growing space $\chi$ measured from the radial direction; $V 7, V 8, V 9$ - airflow velocity at the boundaries $A 7, A 8, A 9$ along the axis $x_{2} ; U 7, U 8, U 9$ - airflow velocity at the boundaries $A 7$, $A 8, A 9$ along the axis $x_{1}$.

The calculation of the temperature dependence of the coolant at the outlet of the cooling tower in changing relative humidity and setting a fixed angular velocity of rotation of the air flowis are presented below. 
Table 1. Initial design parameters of the industrial cooling tower and laboratory model.

\begin{tabular}{|c|c|c|}
\hline & $\begin{array}{c}\text { Industrial } \\
\text { cooling tower }\end{array}$ & Laboratory model \\
\hline \multicolumn{3}{|c|}{ Sprinkler characteristics } \\
\hline Sheet thickness, $\mathrm{mm}$ & 31 & 3 \\
\hline The distance between adjacent sheets, $\mathrm{mm}$ & 6 & 2 \\
\hline Sprinkler height, $\mathrm{m}$ & 2.45 & 0.025 \\
\hline Irrigation area, $\mathrm{m}^{2}$ & 5024 & 2.0096 \\
\hline \multicolumn{3}{|c|}{ Cooling tower geometry } \\
\hline Tower radius, average, $\mathrm{m}$ & 30 & 0.3 \\
\hline Tower height above the nozzle, $\mathrm{m}$ & 88.5 & 0.875 \\
\hline Distance to the water mirror, $\mathrm{m}$ & 3.5 & 0.124 \\
\hline \multicolumn{3}{|c|}{ The parameters of heat carrier } \\
\hline $\begin{array}{l}\text { Air flow of the cooling tower (preliminary value), } \\
\mathrm{m}^{3} / \text { hour }\end{array}$ & 29842560 & 2260 \\
\hline Air humidity, $\%$ & 50 & 50 \\
\hline Atmospheric air temperature, ${ }^{\circ} \mathrm{C}$ & 20 & 20 \\
\hline Air pressure, mm Hg. Art. & 750 & 750 \\
\hline $\begin{array}{l}\text { Circulating water consumption of the cooling tower, } \\
\qquad \mathrm{m}^{3} / \mathrm{h}\end{array}$ & 32000 & 1.8 \\
\hline $\begin{array}{c}\text { Circulating water temperature at the inlet to the } \\
\text { cooling tower, }{ }^{\circ} \mathrm{C}\end{array}$ & 40 & 40 \\
\hline
\end{tabular}

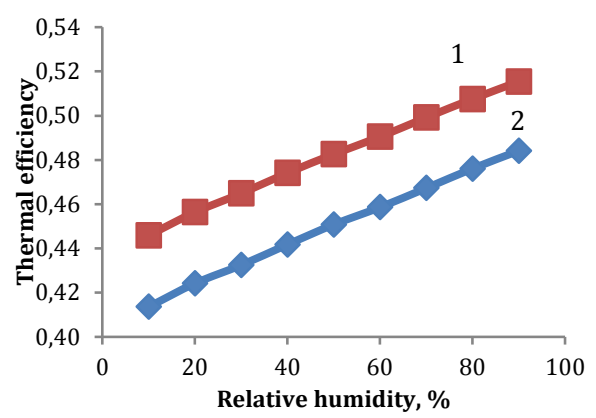

a)

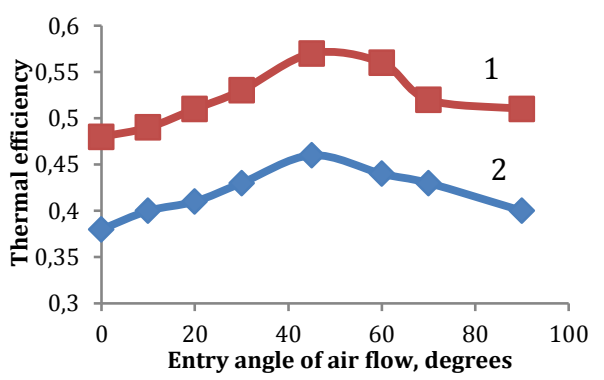

b)

Fig. 2. The plot of the thermal efficiency versus the relative air humidity at the entrance to the cooling tower at $\chi=20$ degrees (a) and the plot of the thermal efficiency when setting the angle of entry of the air flow $\chi$ from 0 to 90 degrees (laboratory model of cooling tower and full-scale (industrial) cooling tower) (b).

With an increase in the relative humidity of the incoming air, there is a directly proportional increase in the efficiency of the cooling tower, determined by the increase in the value of its thermal efficiency (Fig. 2, a). When a fixed angle of entry of air flow into the laboratory cooling tower at $\chi=20$ degrees in the range of relative humidity $\varphi$ lying in the range from 40 to $70 \%$ is installed, an increase in the efficiency of the cooling tower to $10 \%$ is observed compared to the case of $\chi=0$ degree. In the range of $\varphi$ from 10 to 40 and from 80 to $90 \%$ a slight slowdown in the growth of efficiency is observed. Thus, the optimum humidity range for the air flow entering the cooling tower should be in the range of 40 to $70 \%$. The calculation of the temperature dependence of the coolant at the exit of the cooling tower in the face of varying the angle of entry of air flow into the cooling tower is considered below (Fig. 2, b). The highest efficiency of the cooling tower operation at a fixed ratio of air and water flow rates $Q_{a} / Q_{w}=1.07$ falls on the values of the angle of air flow entering the laboratory cooling tower, lying in the range from 45 to 53 degrees (Fig. 2, b). With a shift in 
the balance between incoming water and air flow $Q_{a} / Q_{w}=0.35$, there is an insignificant overall decrease in the thermal efficiency of the cooling tower, especially at angles of entry of air flow greater than 60 degrees. For the laboratory model and the industrial cooling tower the nature of the change in the dependence of thermal efficiency when setting the angle of entry of air flow $\chi$ from 0 to 90 degrees is the same. Diagram of the dependence of thermal efficiency on the angle of entry of the air flow $\chi$ and the magnitude of the temperature difference between the coolant $T_{w \text { in }}$ and atmospheric air $T_{a}$ in $\left(1-15^{\circ} \mathrm{C}, 2-25^{\circ} \mathrm{C}, 3-35^{\circ} \mathrm{C}\right)$ for the laboratory model of the evaporative cooling tower is shown in Fig. 3.

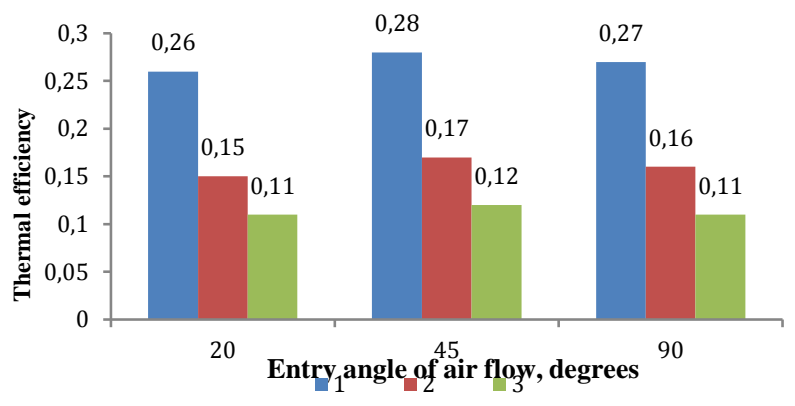

Fig. 3. Diagram of the dependence of thermal efficiency on the angle of entry of the air flow $\chi$ and the magnitude of the temperature difference between the coolant $T_{w}$ in and atmospheric air $T_{a}$ in $\left(1-15^{\circ} \mathrm{C}, 2-25^{\circ} \mathrm{C}, 3-35^{\circ} \mathrm{C}\right)$ for the laboratory model of the evaporative cooling tower.

The diagram shows that thermal efficiency is determined by the magnitude of the temperature difference between the coolant $T_{w i n}$ and atmospheric air $T_{a}$ in. The most efficient cooling of the coolant in the cooling tower sprinkler is observed when the angle of entry of air flow into the growing space is $\chi=45^{\circ}$ (thermal efficiency is about 28\%) (Fig. 3).

\section{Discussion of the numerical simulation results}

Numerical experiments show that efficient evaporation can also be achieved at high humidity of the incoming cooling air. At the same time, thermal efficiency increases significantly with a decrease in the temperature of atmospheric air at the entrance to the cooling tower. With an increase in the relative humidity of the incoming air, there is a directly proportional increase in the efficiency of the cooling tower, determined by the increase in the value of its thermal efficiency (Fig. 2, a). Distribution of T, $\psi$ inside the cooling tower, shows that the heat flux, passing through the internal sprinkler system, changes its shape many times and gives off its energy only through its outer surface. This is an extensive way to release heat. To improve heat transfer, it is necessary to turbulize the flows inside the cooling tower with the use of louvres directing the movement of air, set at an angle at which the maximum thermal efficiency of the cooling tower is achieved. Analysis of the distribution fields of the simulated cooling tower parameters shows that the flow of atmospheric air along the path of its movement, in addition to the heat flux, encounters various elements of the system from which it also takes thermal energy, losing its effectiveness when working with heat flux. It is necessary to get airflow directly to the place of direct contact with the heat flow. Thus, it is necessary to ensure the possibility of taking air directly from the atmosphere (without contact with the coolant) with the direction of the cooling air masses directly into the heat exchange zone with water passing through this zone while minimizing the missing heat exchange contacts with the jet water flows under the sprinklers and aerodynamic resistance. As the 
analysis of the current function distribution fields shows, the "dead" zones in the air movement inside the cooling tower, located under the irrigator, are eliminated by selecting the angles of entry of the air flow into the growing space based on the current hydrometeorological conditions and the working temperature of the coolant. The correct choice of the range of changing the angles of entry of air into the cooling tower can ensure the creation of the maximum possible area and time of thermal contact of water flows and atmospheric air.

\section{Conclusion}

Using the conducted numerical simulation, the optimal parameters of the cooling tower operation, at which the most efficient evaporation of the coolant can occur, were determined. Numerical solution of the boundary value problem for a system of nonlinear fourth-order ordinary differential equations with boundary conditions allows calculating the influence of various parameters: such as water temperature in front of the sprayer, type of sprayer, its installation angle, temperature and humidity, temperature and water flow, and other parameters affecting cooling capacity of the cooling tower. Computer simulation of real installations and modes and comparison with the data of calculations for the designed laboratory installations confirms the validity and reliability of the model.

This study was performed with the financial support of the RF Ministry of Education and Science, President Grant \#NSh-3492.2018.8

\section{References}

1. L. Berman, Evaporative cooling of circulating water (Moscow, 1957)

2. M. Baranova, A. Gavrilov, K. Chikhachev SNRSHU 17, 8-17 (2011)

3. R. Ganiev, Proc. of the XXI Inter. Conf. 417-421 (2013)

4. N. Gusinskaya, R. Nigmatulin, Therm. Eng. 48, 682-686 (2001)

5. C. Schulze, CIRP 69, 277-282 (2018)

6. A. Dhorat, M. A. Al-Obaidi, I. M. Mujtaba, Therm. Sci. Eng. Prog. 9, 30-43 (2019)

7. L. Xia, Appl. Therm. Eng. 105, 1051-1060 (2016)

8. Q. Guo, Appl. Therm. Eng. (2019)

9. G. Dashkov, NRAS 1, 96-106 (2007)

10. R. Nigmatulin, A. Soloviev, Creating a mathematical model of the flow of multiphase media inside the cooling tower (RFBR report No. 12-08-00026, Moscow, 2013)

11. V. Gorbenko, Instructions for use of tower cooling towers at thermal power plants (M, STSTI, 1972)

12. V. Kalatuzov, E 1, 19-24 (2002)

13. A. Solovyev, K. Chekarev, D. Solovyev, PIASPA 43, 173-182 (2018)

14. A. Solovyev, A. Pustovgar, L.Shilova, PE 165, 1275-1280 (2016)

15. R. Nigmatulin, D. Soloviev, Basics of hydromechanics (Moscow, 2012)

16. M. Vukalovich, S. Rivkin, A. Alexandrov, Tables of thermophysical properties of water and water vapor (Moscow, SPH, 1969)

17. Id diagram of humid air [Electronic resource]. URL: https://iddiagram.ru/index.php (access date: 02/19/2019) 